\title{
LA BIBLIOFARMACIA DE KATE CHOPIN O LA LECTURA COMO INTOXICACIÓN
}

\author{
J osé M aría R odríguez G arcía \\ Cornell University
}

RESUMEN: Uno de los principales campos semánticos empleados en The Awakening (1899), de Kate Chopin, es el de la intoxicación y el envenenamiento, que hasta ahora apenas ha sido mencionado. En la primera parte del presente ensayo señalo y comento todas las apariciones significativas en la novela de palabras como "narcotic", "intoxicant", "sting", "chloroform", "venom", e incluso "drug [store]", cuyos referentes en la trama son la lectura de novelas y cartas románticas, el disfrute de la música de Frédéric Chopin, el erotismo extramatrimonial y el contacto solitario con fuerzas sublimes como el océano. En esta narración, los distintos personajes encaran sus experiencias románticas unas veces de manera alopática y otras de manera homeopática. En la segunda parte del ensayo presento una economía profiláctica de las experiencias y emociones románticas. Con este fin recurro a las ideas de K enneth Burke y J orge Larrosa sobre los efectos alternativamente curativos y dañinos que la literatura puede tener sobre el lector. Finalmente, extrapolaré dicha economía a la situación lectora del alumnado universitario que se encuentra por vez primera, en la clase de literatura norteamericana, con una novela de protagonista autodestructivo.

ABSTRACT: O ne of the most important yet also most neglected sets of images in Kate Chopin's The Awakening (1899) is that of intoxication and poisoning. In the first half of this essay I trace and discuss all the noteworthy occurrences in the novel of such words as "narcotic", "intoxicant", "sting", "chloroform", "venom", and even "drug [store]", whose main referents in the plot are the reading of romantic novels and letters, listening to F rédéric Chopin's music, out-of-wedlock eroticism, and the solitary contact with sublime forces such as the ocean. In the narrative, the main characters often approach their romantic experiences in either an allopathic or a homeopathic manner. In the second half of the essay I articulate a prophylactic economy of romantic experiences and emotions. To this end I resort to the ideas on the alternately healing and damaging effects of literature put forth by Kenneth Burke and J orge Larrosa. I will then extrapolate one such economy from the situation of the characters in The Awakening to that of the undergraduate students in Spain who discover a novel with a self-destructive protagonist for the first time in an A merican literature course. 
A partir de finales de los años ochenta del siglo XX, se produce una revalorización de los enfoques éticos en la literatura y el pensamiento crítico, provocada, entre otras razones, por la visible fatiga que las teorías del giro lingüístico y la desaparición del autor comienzan a experimentar hacia esas mismas fechas; por la entusiasta recepción de que son objeto los escritos sobre el binomio identidad/ alteridad del primer M ijaíl B ajtín, de Emmanuel Lévinas y del último M ichel Foucault; y por la novedosa atención que a temas y enfoques éticos prestan diversos críticos desconstructivos (como J. Hillis M iller) y neoaristotélicos (como Wayne C. B ooth). Este clima favorable a los estudios éticos coincide con el auge de un movimiento interdisciplinario conocido como Critical Legal Studies (su representante más conocido es Stanley Fish), cuyos seguidores utilizan textos literarios para discernir espinosos problemas legales y viceversa. A simismo, a partir de más o menos 1990 se abren camino en España y Estados Unidos los modelos pedagógicos para la enseñanza de la literatura centrados en la experiencia de un lector aventurero, dispuesto a perderse y reencontrarse tras un accidentado viaje de la imaginación, más que en la correcta organización de un currículo administrado rigurosamente por el profesor. Comoquiera que estos modelos equiparan el acto de leer con las estrategias de extravío personal y autoindagación propugnadas por los estudios éticos, se hace necesaria una aproximación interdisciplinaria al acto de leer que incorpore, en un mismo ejercicio interpretativo, las herramientas de la crítica ética y los model os desjerarquizados de lectura.

Para llevar a cabo dicho ejercicio, he escogido una novela recientemente canonizada cuya protagonista concibe su experiencia artística y vital como una aventura desequilibrante de su identidad, en la cual reiteradamente toma decisiones al margen de normas sociales y legales. Me refiero a The Awakening (1899), de $\mathrm{K}$ ate $\mathrm{Chopin}$, donde se representa el desequilibrio de la identidad socialmente construida como el abandono a los efectos de un narcótico, un licor y una picadura venenosa. L os actos concretos de la protagonista de Chopin que sirven como referentes inmediatos de la experiencia de la intoxicación son su lectura de novelas románticas, la catarsis que le provoca la música de Frédéric Chopin, el erotismo extramatrimonial y el contacto solitario con fuerzas sublimes como el océano. En la novela, las experiencias románticas se presentan de manera alopática (es decir, se las puede neutralizar por medio de un antídoto tan potente como pueda ser la asunción de pesadas cargas domésticas) y homeopática (es decir, se las puede administrar en pequeñas dosis que protejan al sujeto romántico de una intoxicación mayor y más nociva). Tras explicar la función de este campo semántico en la novela de Chopin, en la segunda parte de mi ensayo propongo una economía profiláctica de las emociones y experiencias románticas. Para ello echaré mano de hipótesis sobre los efectos recíprocamente curativos y agresores de la 
literatura desarrolladas por $K$ enneth B urke en Estados U nidos y J orge L arrosa en España. Finalmente, de mi análisis de The Awakening extrapolaré una economía profiláctica afín específicamente aplicable a los jóvenes lectores (dentro y fuera del mundo académico) que se acercan por vez primera a una novela de protagonista arriesgadamente transgresora.

The Awakening (1899) es hoy ya una referencia esencial para estudiar la situación de la mujer en la cultura norteamericana de finales del siglo XIX. A través de tres figuras femeninas secundarias Chopin propone otras tantas alternativas de construcción de la identidad femenina distintas a la elegida por Edna Pontellier, protagonista de la narración. La alternativa negativa, fruto del determinismo económico más que de la elección libre, es la proletaria M ariequita, una hispana dedicada a la recolección de marisco, en régimen de subsistencia, en una isla de Louisiana, y por tanto marginada económicamente por su sociedad, y, se sugiere, explotada incluso sexualmente (capítulo XVI). La primera alternativa positiva la proporciona una profesora de piano de edad madura, la solitaria $M$ ademoiselle Reisz, quien ha elegido conscientemente una vida pequeño-burguesa consagrada a la enseñanza y el arte, para mantener así la misma autosuficiencia económica, afectiva e intelectual a la cual cree aspirar, en algunos momentos, también Edna (capítulo IX). La segunda alternativa positiva, fruto a un tiempo de la presión social y de la afinidad personal por un rol matrimonial convencional, es la de convertirse en perfecta ama de casa y madre de familia, como la exuberante Madame Ratignolle, definida como una "mother-woman": mujer que se realiza en el matrimonio y la maternidad (capítulo IV).

Por su parte, M onsieur Ratignolle, un pequeño comerciante y experto cocinero que ayuda a su esposa en las tareas domésticas, aparece como un parangón de virtud, devoto de su familia y de su comunidad: "M onsieur R atignolle was one of those men who are called the salt of the earth. His cheerfulness was unbounded, and it was matched by his goodness of heart, his broad charity, and common sense ... The R atignolles understood each other perfectly. If ever the fusion of two human beings into one has been accomplished on this sphere, it was surely in their union" (159-60)ํ. A squeada por la cálida felicidad que emana del hogar de

1. M is citas del texto de The Awakening provienen de la edición de González Groba (1997). Hay traducción castellana, no exenta de problemas, a cargo de Olivia de Miguel: El despertar (Madrid: Hiperión, 1986). A unque en el capítulo IV se afirma que A dèle Ratignolle pertenece al tipo de mujeres que "worshiped their husbands, and esteemed it a holy privilege to efface themselves as individuals", su marido hace lo propio y ambos conviven en un plano de armónica igualdad (99). Showalter sugiere que la maternal A dèle es la figura que compensa a Edna por la prematura pérdida de su madre, mientras que $M$ ademoiselle Reisz sustituye al amante romántico que la protagonista no ha tenido, de ahí que las piezas de Frédéric Chopin interpretadas por la pianista arranquen de Edna un "passionate sobbing" o sollozo apasionado (1994: 46). 
Ios Ratignolle, en sus pensamientos E dna dice preferir una cena medicinal a base de hierbas curativas que limpien su conciencia de ilusiones domésticas: " B etter a dinner of herbs"' (160). En otras palabras, Edna prefiere la ingestión de sustancias medicinales a las nutritivas comidas familiares, de igual forma que prefiere las lecturas románticas a la sustancia de la vida cotidiana responsable ${ }^{2}$. Tras dar el paso de separarse de su marido, la protagonista de Chopin no elige ni la vida libérrima, aunque desarraigada, de una militante feminista como la autora coetánea Charlotte Perkins Gilman, ni el compromiso autolimitador de M ademoiselle Reisz, ni mucho menos el amor maduro de otra relación de pareja, sino que busca refugio en la evasión imaginativa de todo lo social, búsqueda que en la novela se expresa como intoxicación, enajenación, exploración de la soledad y alienación voluntaria de la familia y la comunidad. A sí, "to dream and to be al one and unmolested" designa la situación más buscada por Edna a lo largo de la novela, mientras que "freed of responsibility" designa su problemática relación con la ética de la responsabilidad $(162,150)$. Con todo, la expresión más reveladora de su deseo de evasión ilusionista y autoexclusión acaso sea la equiparación reiterada de las praderas de K entucky por las que corría de niña, para escapar de la disciplina de un hogar rigorista, con el océano descubierto en el presente de la narración y en el cual se adentra para aprender a nadar. La propia Edna describe su ideal de fijación introspectiva, en referencia a esas carreras por la hierba y esas incursiones natatorias, como una deriva realizada "idly, aimlessly, unthinking, and unguided", palabras que cuestionan, de nuevo, el alcance emancipador que muchos críticos han otorgado a los actos de renuncia social del personaje (109-10, 235).

La expresión con que Edna señala la diferencia entre su despertar imaginativo y la domesticidad del matrimonio amigo es "'life's delirium'". La imagen alucinatoria irrumpe, como un fogonazo, en la mente de Edna sin que ésta sea capaz de interpretarla o de controlar los efectos que pueda tener en su conciencia y en sus acciones futuras. El contexto narrativo en que aparece la expresión debe leerse, en mi opinión, como una crítica que la autora implícita hace de la intensa agonía existencial y el riesgo, y como una defensa (frente al prejuicio de Edna) de la felicidad armónica:

2. I rónicamente, a los Ratignol le se les atribuye la capacidad de administrar pequeñas dosis de felicidad a sus convecinos a través de su negocio de botica y estanco: "M onsieur Ratignolle owned and conducted a drug store which enjoyed a steady and prosperous trade [and] stood well in the community" (158). 
The little glimpse of domestic harmony which had been offered her, gave her no regret, no longing. It was not a condition of life which fitted her, and she could see in it but an appalling and hopeless ennui. She was moved by a kind of commiseration for $\mathrm{M}$ adame Ratignolle, - a pity for that colorless existence which never uplifted its possessor beyond the region of blind contentment, in which no moment of anguish ever visited her soul, in which she would never have the taste of life's delirium. Edna vaguely wondered what she meant by "Iife's delirium." It had crossed her thought like some unsought, extraneous impression. $(160)^{3}$

El "blind contentment" de A dèle R atignolle aparece aquí como contrapunto emocional, más que epistemológico, de los "blind impulses" de Edna (130). Pese a las palabras aprobatorias de la narradora, quien considera a los R atignolle como la encarnación del companionate marriage, en el cual los esposos se tratan el uno al otro en un plano de afectuosa igualdad, Edna ve el enlace conyugal en términos melodramáticos, como un sacrificio y una renuncia.

La institución del matrimonio en la novela de Chopin ha sido tratada pormenorizadamente por la americanista Wai Chee Dimock en un importante ensayo (publicado en dos versiones que muestran algunas diferencias argumentativas entre sí), el cual citaré repetidamente a lo largo de este trabajo, entre otras razones, porque muchos críticos que con posterioridad han escrito inteligentemente sobre The Awakening han optado, sin embargo, por no hacer mención de él. Según Dimock, en la sociedad norteamericana de la segunda mitad del siglo XIX, la jurisprudencia en que se inspiran los contratos civiles y mercantiles normalmente invoca la comunidad de sentimientos que dos o más individuos expresan subjetivamente. El vínculo contractual puede apoyarse en un sentimiento subjetivo en la medida en que este último evidencia, ante todo, la voluntad de una transacción 0 una comunidad de propósitos. Por contra, la conducta de Edna ilustra la nueva jurisprudencia del derecho a la intimidad y al aislamiento (i.e., "to be let alone") propugnada en 1890 por Samuel D. Warren y Louis D. B randeis en su ensayo "The Right to Privacy". El derecho a la intimidad no propugna el acercamiento de dos subjetividades, sino que se formula como una conquista realizada de manera "adversarial", expulsando violentamente de la esfera de la interioridad a los "antagonists" del sujeto (palabra que aparece en la conciencia de Edna cuando ésta visualiza a los niños en la p. 234 de la novela, momentos antes de su sui-

3. Sobre la censura autorial del personaje de Edna, en especial de su visión condescendiente de otras mujeres así como de su tendencia a emular formas de control despótico típicamente patriarcal es (con sus sirvientes y con sus amantes), véase Schweitzer (1994: 170-78). 
cidio) de derecho así concebido (Dimock 1996: 191-97). El peligro inherente a esta filosofía de la intimidad en el sistema jurídico estadounidense, en un momento en el cual todo derecho contractual se basaba en el "moral subjectivism", es que autoriza a individuos como Edna a utilizar una doble articulación en la adjudicación y denegación de derechos, que ella maneja a su antojo:

If only to protect herself, then, if only to free herself from the "chain" which others will use absolutely, and use absolutely to bind her, Edna must insist that "nobody has any right," that the enthralling chain lies in no other hands but her own. The propositions "Edna has a right" and "nobody has any right" operate, then, not as a contradiction, but as the two faces of a single principle. What is crucial for the right holder, it seems, is not so much self-fashioning as negative attribution, the refashioning of one's adversary from a potential right holder into a nonclaimant, perhaps even a nonentity. Still, this making of a "nobody," while psychologically understandable and perhaps even pragmatically enforceable, is not so rationally justifiable. (1996: 199)

La novela parte de la premisa utópica de plantear la existencia de un mundo sin "prima facie rights", o sea, un mundo en el cual el lema "mis derechos terminan donde comienzan los de mi vecino" ha sido abolido y en el que, en consecuencia, cada individuo debe buscar activamente la soledad para evitar conflictos y disputas que le hagan recordar los derechos irrenunciables de sus semejantes: "Imagining rights as being somehow intransitive, somehow divorced from the 'chain' that usually accompanies them, the novel also imagines Edna as intransitive, as divorced from the recipients of her actions, so that those actions now seem pertinent only to herself, without consequence for others and apparently not directed against others" (Dimock 1996: 201). Edna desea hacer valer su "personalized reason" sobre la "shareable reason with others", de ahí que, dentro de su matrimonio, evite plantear una "conflict resolution" pacífica, en la cual los cónyuges se reconocerían mutuamente como sujetos de derecho en negociación de sus prerrogativas respectivas. En su lugar, Edna practica sistemáticamente la "dissolution of conflict" consistente en apartarse física y mentalmente de M r. Pontellier sin darle jamás explicaciones de su conducta (Dimock 1996: 202, 204). El epítome de esta fantasía de autonomía absoluta se expresa en las dos frases, citadas numerosas veces por Dimock, "I want to be let alone. Nobody has any right"las frases que Edna utiliza, en conversación con el Dr. M andelet, para arrogarse en exclusiva el papel de individuo arbitrariamente desprovisto de su derecho a la intimidad (229).

El estudioso norteamericano de la dimensión simbólica de los discursos literarios y políticos, Kenneth Burke, utiliza en su obra Permanence and Change (1935; rev. 1984) la expresión oximorónica "dying life" (que aquí podemos opo- 
ner al "life's delirium" de Edna) para describir la percepción condescendiente de quien ve toda forma de domesticidad y autodisciplina como un síntoma de represión (1984b: 289). En una obra inmediatamente posterior, titulada Attitudes toward History (1937; rev. 1984), B urke distingue entre dos tipos de experiencia imaginativa con los cuales se puede salvaguardar a un personaje 0 a un lector de las consecuencias negativas de una eventual disfunción emocional. A esta medicina textual preventiva la Ilama Burke "stylistic prophylaxis". La primera modalidad de profilaxis es la "allopathic hygiene", cuyo nombre deriva del procedimiento médico consistente en administrar al sujeto enfermo un medicamento muy potente destinado a eliminar de raíz su enfermedad ${ }^{4}$. L a profilaxis alopática, por su parte, conllevaría la inmunización preventiva del lector propenso a las vel eidades románticas por medio de una dosis grande de responsabilidades prosaicas, 0 viceversa. La segunda modalidad es la "homœopathic hygiene", consistente en la inoculación o ingestión preventiva de pequeñas dosis de la misma sustancia dañina que, consumida en dosis mayores, causaría una patología, de forma tal que el paciente desarrolle anticuerpos que lo inmunicen frente a la eventualidad de una intoxicación mayor (1984a: 44-46)5.

Resulta muy útil acercarse a los personajes femeninos del entorno de Edna como a sujetos que combaten la experiencia romántica de la búsqueda del absoluto, sometiéndose para ello a tratamientos de profilaxis emocional tanto alopática como homeopática. EI personaje de M adame Ratignolle ilustra la prevención al opática, Ilevada a cabo de forma contundente a través de la maternidad, la cual exige la renuncia, cuando menos momentánea, del egocentrismo romántico en aras de la responsabilidad hacia los seres recién traídos al mundo. Por su parte, el personaje de M ademoiselle Reisz ilustra la inmunización homeopática: la profesora de música vive la soledad relativa de manera imaginativa, a través del arte que practica y consume y de su voluntario aislamiento del mundo social más convencional. Más aún, los modestos recitales vespertinos que la pianista ofrece en

4. La alopatía y la homeopatía son terapias reactivas y no hábitos preventivos con los cuales curarse en salud, es decir, no son formas de profilaxis. Es Burke quien, en su uso metafórico de alopatía y homeopatía, añade una dimensión adicional, higiénica, a la propiamente terapéutica. En la aclaración de estos conceptos encontré de gran utilidad el Diccionario enciclopédico de las ciencias médicas (1985).

5. En un ensayo de 1941, "Ritual Drama as Hub" (incluido en su volumen recopilatorio Terms for O rder, editado por H yman y K armiller en 1964), B urke vuelve a enunciar su concepto de infección homeopática, que ahora tilda de "sinécdoque estilística," la cual puede tener el efecto de inmunizar al lector (incluso al autor) de una obra frente a una eventual infección mayor (132-37). El revelador contraejemplo que proporciona Burke al desarrollar esta nueva metáfora es el de un escritor al cual su adicción alcohólica lo ha privado del control para convocar "spells" o "incantations", es decir, para regular su capacidad de autoabandono en la práctica de la escritura imaginativa. 
Grand Isle tienen el efecto de desatar "a fever of enthusiasm" en su reducido auditorio de veraneantes, quienes después hacen una exégesis de la actuación, racionalizando así los efectos homeopáticos de la música de Frédéric Chopin (122). Por contra, cada vez que escucha esta misma música, Edna se precipita en lo que la narradora, en un pasaje afín, Ilama los "abysses of solitude" $(122,170,106)$. En otras palabras, al revés que la propia E dna, ninguna de sus dos amigas cae víctima de la intoxicación emocional atribuida al romanticismo exacerbado, que en la novela se retrata como el abandono a los impulsos de afirmación del yo en una búsqueda solitaria de un ideal de autonomía absoluta. Dicho ideal es realizable sólo como contacto con el ámbito de lo sublime, o sea, en la fusión autodestructiva con la naturaleza o en la enajenación del arte irracional.

El principal interlocutor masculino de Edna en su despertar imaginativo, erótico y artístico es el joven R obert L ebrun, quien pese a su introversión sexual consigue dar expresión verbal a tres de las inquietudes románticas de la protagonista: Ia necesidad de la soledad, la búsqueda de un alma gemela y la exploración de una nueva identidad forjada al margen de las convenciones sociales, o lo que es lo mismo, basada principalmente en las experiencias del abandono a los instintos y el riesgo. Robert es capaz de experimentar la realidad desde el punto de vista emocional y artístico de quien, como $\mathrm{E}$ dna, busca despertar a una vida más auténtica y espontánea. Sin embargo, como apuntaré más adelante, R obert, al igual que M ademoiselle Reisz (la amistad de ambos sugiere su comunidad de valores), es consciente también de la inaplicabilidad de los ideales románticos, en estado puro, a la existencia diaria. Esta lucidez es lo que une a ambos personajes al tiempo que los distingue de Edna.

El capítulo $X$ es clave para el desarrollo narrativo y simbólico del despertar de Edna en la compañía de su joven admirador. Como Robert le está enseñando a nadar ese verano, dicho despertar lleva consigo la exploración por parte de ella de nuevos horizontes de libertad física en la playa, aventurándose cada vez más lejos de la orilla. L a finalización de las clases de natación se produce en la misma tarde-noche en que Edna descubre la importancia del arte (la música) para su despertar y en que siente por vez primera el aguijoneo del deseo adúltero por R obert, a quien dice: "A thousand emotions have swept through me to-night. I don't comprehend half of them. Don't mind what I'm saying. I am just thinking aloud... I wonder if any night on earth will ever again be like this one ... There must be spirits abroad to-night" (125). A estas palabras, aún demasiado torpes para articular adecuadamente el despertar artístico, erótico y autónomo de Edna, encuentra Robert un correlato objetivo en la fábula improvisada de un espíritu marino que 
recorre la isla para encantar a los veraneantes: "But to-night [the spirit] found M rs. Pontellier. Perhaps he will never wholly release her from the spell" (126) ${ }^{6}$. A unque $E$ dna reacciona con forzada indignación ante quien ha osado interpretar su esencia más íntima, tanto ella como Robert se dan cuenta de que el rasgo que los une es su romanticismo compartido: "He did not mind the entreaty, but the tone with its delicate note of pathos was like a reproach. He could not explain; he could not tell her that he had penetrated her mood and understood" (126)7.

No obstante el peso narrativo que acabo de adjudicar a R obert, el rasgo definitorio de las restantes figuras masculinas de autoridad que aparecen en The Awakening, como por ejemplo el Dr. M andelet, M r. Pontellier y el padre de Edna, es su ceguera ética y epistemológica, es decir, su incapacidad para entender la realidad desde el punto de vista de otra persona, según el método a través del cual esa persona transforma sus emociones en actos. Con todo, en distintos momentos de la narración, los tres desean y buscan activamente la felicidad de Edna. Baste decir que ésta no es traicionada ni utilizada sexualmente por hombre al guno en la novela (ni tan siquiera por el seductor A Icée A robin), sino que ella misma decide, primero, salir apresuradamente de la casa paterna para, en un acto de aparente rebeldía filial, contraer matrimonio; después, abandonar a su desconcertado marido ${ }^{8}$, y por último, interrumpir la relación adúltera con A robin al comprobar que su affaire se agota en el mero disfrute sexual. A unque quienes han escrito sobre The Awakening han preferido, por lo general, pasar por alto la interioridad de los personajes masculinos, me parece del todo necesario señalar que varios de los hombres que habitan el texto de Chopin presentan ciertos rasgos en común al margen de sus presuntos prejuicios machistas. A sí, una característica que comparten Mr. Pontellier, A robin y Robert es el convencimiento de que el despertar

6. De hecho, la palabra "spell" (en su acepción secundaria de "momento" o "instante") se asocia, en un mismo pasaje utilizado dos veces en la novela, con la voz de Robert, con la del espíritu creado por éste y con la del mismo océano: "The voice of the sea is seductive; never ceasing, whispering, clamoring, murmuring, inviting the soul to wander for a spell in abysses of solitude; to lose itself in mazes of inward contemplation" (106 y 234).

7. Rankin recalca aún más la empatía entre ambos personajes al atribuirles una misma conciencia lectora: los dos leen la literatura romántica e interpretan sus propias emociones y el mundo en general con la frescura, ingenuidad y abandono de "first-time readers of novels" (1988: 150).

8. Dimock menciona dos razones, en su análisis del retrato de M r. Pontellier en el capítulo III como un marido insensible, para tildar dicha caracterización de irónica, es decir, filtrada por la percepción subjetiva de Edna, que la narradora se habría apropiado aquí silenciosa y transitoriamente: en primer lugar, la impaciencia de M r. Pontellier no encaja con su conducta posterior de tolerancia, civismo y afecto; y en segundo lugar, el comportamiento de Edna en el mismo capítulo es bastante más insensible que el de su marido (Chopin 92-93; Dimock 1990: 36-37; 1996: 206-07). 
romántico e imaginativo es tan sólo (para usar dos de los lugares metafóricos de la novela) una "isla" aparecida de repente en el inmenso "mar" del negotium. Para los tres amantes de Edna, los códigos románticos tienen una aplicabilidad por natural eza efímera y pueden ser contemplados, al ternativamente, como síntoma de inmadurez (como hace M r. Pontellier), como instrumento para incrementar el codiciado prestigio donjuanesco en la masculinista sociedad Creole (A robin), o como profilaxis homeopática contra la enajenación (Robert). En el status que queramos asignar a la experiencia romántica en The Awakening está, pues, una de las claves interpretativas de la novela. Paralelamente, en la administración que hagamos de dicha experiencia, en dosis mayores o menores, reside su utilidad didáctica como instrumento de exploración ética a través de la lectura profiláctica.

Uno de los ensayos más útiles y más profundamente responsables sobre la teoría de la literatura realizados en España desde la innovadora perspectiva de la ética de las emociones se debe a J orge L arrosa. En La experiencia de la lectura. Ensayos sobre literatura y formación, este profesor de Ciencias de la Educación define la literatura como una exploración de "Io real con la mediación de lo irreal", dirigida explícitamente a un lector que es a un tiempo activo y receptivo, es decir, que utiliza la lectura como "intensificador" y "multiplicador vital" (1996: 121). Larrosa distingue, en términos terapéuticos y platónicos, entre dos mediaciones literarias: primera, la que te ayuda a vivir la vida, incluso en sus aspectos menos agradables, con los que busca reconciliarte a través de la responsabilidad; y segunda, la que te droga como un narcótico y permite que te evadas momentáneamente de los problemas, sin que te enfrentes nunca a ellos en busca de una solución duradera.

Si bien existe mucha literatura que causa daño, como insiste Larrosa, reconocer la fuerza destructora de esos textos puede ayudarnos a administrar su influencia de manera homeopática. Ello nos permitiría protegernos contra la enajenación a la vez que experimentamos con nuestra identidad para aprender algo más sobre nosotros mismos y sobre las relaciones humanas. A unque el pasaje en que Larrosa resume este argumento sea largo, me parece lo suficientemente importante como para reproducirlo casi en su totalidad:

La literatura es realmente peligrosa. Por eso la prueba de fuego de la identidad (de la humanidad instituida en nosotros) consiste en aprender a dominar el mal que la experiencia de la literatura trae consigo. Por eso el orden moral basado en la experiencia, en la individualización, en el que cada uno sea cada uno, no puede imponerse sino mediante la desactivación del desafío de la experiencia de la literatura. Y mediante el olvido de esa desactivación. Hay que neutralizar el veneno, 
el fármaco, el encantamiento. Hay que olvidar, quizá dolorosamente, no sólo lo que el fármaco nos abría como posibilidad de experiencia, sino también, y sobre todo, lo que de violencia y de sometimiento hay en eso que somos. (1996: 89) ${ }^{9}$

Para L arrosa, pues, la literatura es una droga y nuestra tradición cultural una suerte de bibliofarmacia. Como si se tratase de fármacos administrados al espíritu 0 a las emociones, al gunos libros tienen la facultad de hacernos perder las inhibiciones y liberarnos del control que nuestra conciencia social, a menudo excesivamente disciplinaria, ejerce sobre nuestras pasiones y deseos inconscientes. Como muchas sustancias psicoactivas, la literatura puede crear adicción. A simismo, como la profilaxis homeopática, puede tener, en pequeñas dosis, el efecto beneficioso de prevenir una infección mayor. Por ejemplo, puede poner un poco de riesgo, aventura o irracionalidad en la vida ordenada de un lector maduro que ayude a éste a sobrellevar mejor las mismas responsabilidades familiares que a Edna Pontellier se le hacen insoportables.

En The Awakening, obra impresionista y precursora del modernism angloamericano, las cuatro experiencias de la autoexpresión y el riesgo románticos, la embriaguez artística y el erotismo espontáneo se equiparan, literalmente, con un narcótico y con la punzada venenosa de un aguijón, es decir, con sustancias de efectos al ternativamente liberadores y agresores. En el capítulo VII, Edna se permite hablar de sus emociones, con mayor franqueza de la habitual, con M adame Ratignolle, en un acto verbal que se representa como una borrachera: "She was flushed and felt intoxicated with the sound of her own voice and the unaccustomed taste of candor. It muddled her like wine, or like a first breath of freedom" (113). En el capítulo X, el aprendizaje de la natación le permite ampliar su radio de autonomía física (ahora se al eja de la orilla, donde se quedan los demás personajes), que es caracterizada una vez más como una intoxicación: "She would not join the groups in their sports and bouts, but intoxicated with her newly conquered power, she swam out alone" (124). En el capítulo XXV, el riesgo romántico reaparece en la forma de apuestas en el hipódromo, que Edna realiza de manera compulsiva, casi ludopática, en la peligrosa compañía del seductor A robin: "She played for very high stakes, and fortune favored her. The fever of the game fla-

9. En El malestar en la cultura (1930), especial mente en las secciones 2 a 4, Freud se explayó sobre la "narcotización de la sensibilidad" y la "ligera narcosis en que nos sumerge el arte", así como sobre el "cariz tóxico de los procesos mentales" consistentes en la subjetivización de la felicidad en momentos encaminados exclusivamente a "satisfacer una pulsión instintiva indómita, no sujeta por las riendas del yo" (1970: 17-49; las citas provienen de las págs. 33, 24, 22 y 23). Resulta un tanto sorprendente, en el erudito libro de Larrosa, la ausencia de Freud, aunque no tanto la de Burke (él mismo un temprano exponente de la crítica psicoanalítica), a quien apenas se conoce fuera del dominio anglófono. 
med in her cheeks and eyes, and it got into her blood and into her brain like an intoxicant" (183).

En el mismo capítulo se establece la conexión entre la intoxicación producida por las apuestas y la causada por el contacto físico con A robin: "[A lcée A robin's] presence, his manners, the warmth of his glances, and above all the touch of his lips upon her hand had acted like a narcotic upon her" (187). A simismo, cuando en la cena que E dna ofrece, para celebrar su separación de M r. Pontellier, el hermano pequeño de Robert, el aún adolescente Victor, flirtea descaradamente con la anfitriona, ésta le tapa la boca con la pal ma de la mano. Victor reacciona besando esa mano, con lo que provoca una nueva sensación narcótica en Edna: "The touch of his lips was like a pleasing sting to her hand" $(204)^{10}$. Por último, en el reencuentro de Edna y Robert, en el capítulo XXXVI, los dos se besan por primera y última vez, en un beso voluptuoso que inunda el ser de él como si se tratase de un veneno inoculado por medio de una picadura: "She leaned over and kissed him-a soft, cool, delicate kiss, whose voluptuous sting penetrated his whole being- then she moved away from him" (224).

Numerosos críticos que han defendido la dimensión ética inherente a los actos de lectura y escritura han señalado la importancia que para cualquier ente participante en el proceso narrativo (desde el autor empírico hasta el lector empírico) tiene el momento de confrontación con un intertexto biográfico. Tal intertexto puede comprender desde la vida de un personaje desarrollada narrativamente en la obra que se está leyendo (ética lectora) hasta una imagen autobiográfica del propio autor interiorizada como recuerdo traumático y dramatizada en la misma obra con ánimo de sacudir la conciencia del lector (ética autorial y lectora). Tomando como referencia los pasos que un personaje, narrador o sujeto autobiográfico recorre en el texto, el lector puede emitir primero una respuesta emocional al suceso narrado, para después acometer un proceso de distanciamiento crítico que lo puede llevar o no a la asunción de responsabilidad por un otro con-

10. El contraejemplo negativo de una sustancia que adormece los sentidos en lugar de agudizarlos es, por supuesto, el del cloroformo, que representa el estado de adormecimiento previo al (para Edna) falso despertar de la maternidad, falso por cuanto no comporta más que obligaciones sociales: "She recaIled faintly an ecstasy of pain, the heavy odor of chloroform, a stupor which had deadened sensation, and an awakening to find a little new life to which she had given being...." (228). También es interesante el uso que se da en la novela a los efluvios del alcohol como instrumento que allana la difícil convivencia de Edna con las visitas de compromiso, incluido su padre, quien es retratado como "an expert at concocting strong drinks. He had even invented some": "The dinner was excellent. The claret was warm and the champagne was cold, and under their beneficient influence the threatened unpleasantness melted and vanished with the fumes of the wine [...] The champagne was cold, and its subtle fumes played fantastic tricks with Edna's memory that night" (176-78). 
cebido como interlocutor constante del sujeto lector y como acicate de sus indagaciones éticas (Nussbaum 1990: 40-43; Rodríguez García 1998: 121-22; Loureiro 2000: 5-8, 23-25, 138-42). Éste es precisamente el camino que Edna podría haber seguido, al comenzar su veraneo en G rand Isle, separándose física y emocionalmente de su marido y juntándose con el mar, con Robert y con la independiente M ademoiselle R eisz.

A través de R obert y M ademoiselle R eiz, quienes conjuntamente representan el oasis homeopático de la novela (la experiencia romántica dosificada), Edna accede a nuevos discursos (musicales, paisajísticos y literarios), los cuales le restituyen la antigua pasión adolescente por la experiencia imaginativa y sensual. En el capítulo VII, que presenta retrospectivamente al gunos episodios de la adolescencia de Edna, incluso se sugiere que la propia protagonista es consciente de haber vivido, antes de su matrimonio con Léonce Pontellier, una existencia romántica paralela en el universo de su imaginación: "Even as a child she had lived her own small life all within herself. At a very early period she had apprehended instinctively the dual life- that outward existence which conforms, the inward life which questions" (106). Tras relatar al gunos episodios de hiperestesia juvenil, la narradora pasa a explicar cómo Edna renunció drásticamente a su romanticismo enfermizo de manera alopática, evitando tras el matrimonio incluso los ocasionales y saludables desahogos homeopáticos que la lectura, la música o la ensoñación le podrían haber proporcionado: "She grew fond of her husband, realizing with some unaccountable satisfaction that no trace of passion or excessive and fictitious warmth colored her affection, thereby threatening its dissolution" (112).

A hora bien, una vez tomada la decisión de regresar al mundo romántico del que voluntariamente se había separado al término de la adolescencia, Edna adquiere unos val ores bien diferentes a los representados por su matrimonio, a los que se entrega incondicionalmente, como si se sumergiese en otro océano de la experiencia ${ }^{11}$. El problema de Edna, tal y como lo veo yo, siguiendo escrupulosa-

11. No se ha señalado suficientemente el hecho de que Edna sea una pequeña rentista: la herencia materna le habría permitido en su momento, si así lo hubiese deseado, mantener la soltería que después lamenta haber perdido (190). Sin embargo, como explican Culley (1976a: 118) y Delbanco (1997: 12224), el código civil de Louisiana, de origen napoleónico, convertía todas las propiedades e ingresos de la mujer, tras el matrimonio de ésta, en patrimonio del marido, de ahí que una importante manifestación del despertar de Edna, muy poco comentada, sea la del individualismo posesivo y mercantil, expresado por ella en la satisfacción que siente al vender sus primeros bocetos pictóricos. De todas formas, es preciso recordar que M r. Pontellier no invoca jamás las atribuciones económicas y jurídicas que le concede el derecho matrimonial de Louisiana. 
mente las pistas de la narración, es que no sigue sucesivamente los tres pasos de respuesta empática, valoración crítica y responsabilidad ética necesarios para llevar a cabo una lectura imaginativa responsable. Por el contrario, ella se queda anclada entre los dos primeros pasos, queriendo llevar a sus últimas consecuencias la identificación apasionada con el rol romántico de individuo alienado en busca del valor inefable de la autonomía absoluta. Por eso Edna, en lugar de ver su nueva receptividad imaginativa como una liberación homeopática de las pesadas cargas asumidas previamente como esposa y madre convencional, considera que la vida de la imaginación y la sensualidad es incompatible con la vida de la responsabilidad y el deber, que la primera no puede llevar a la segunda y viceversa. Edna busca, pues, la liberación al opática, que cree poder obtener con un nuevo tratamiento de choque, estructural mente análogo, aunque de signo contrario, al de su repudio anterior de la imaginación romántica: su rechazo de la esfera doméstica y familiar, y su posterior entrega incondicional a la soledad y la introspección ${ }^{12}$. Siguiendo una argumentación complementaria de la mía, José Ángel García Landa, en su monumental Acción, relato, discurso. Estructura de la ficción narrativa, ha explicado cómo todas las modernas hipótesis de la recepción lectora del texto que exigen del lector un compromiso ético sostienen además que autor y lector operan en una dialéctica, en la cual el significado atribuible a una obra literaria se amolda alternativamente a una necesidad interpretativa concreta- la de un lector particular - y a una visión del mundo precodificada- la del autor (1998: 266-70). Edna, sin embargo, no es una lectora dialéctica, sino totalitaria; no busca el intercambio y flujo de ideas entre el texto leído (las narraciones y ensoñaciones románticas) y el texto lector (su conciencia ética), sino que ansía la identificación de ambos en un continuo sin fracturas ${ }^{13}$. Parafraseando el modelo lector propuesto por el filósofo Richard K earney, añadiríamos que $E$ dna no permite que su "grand narrative" de emancipación romántica entre en diálogo auto-

12. Dimock compara los momentos en que Edna, a salvo de la compañía de su padre, marido e hijos, lee a Ralph Waldo Emerson (181) y en que se confiesa una artista en ciernes ante Mademoiselle Reisz (169), con el famoso pasaje de "Self-R eliance" sobre la introversión egoísta del genio: "I shun father and mother and wife and brother when my genius calls me... Expect me not to show cause why I seek or why I exclude company" (citado en Dimock 1996: 203).

13. Como ha explicado García Landa, existen diversos grados en la "libertad del lector", según se trate de lectores que recurren conscientemente a las mediaciones (entre ellos los profesores) o de los IIamados "básicos" (entre ellos los neófitos de la Filología Inglesa que se acercan por vez primera a una novela como The Awakening). Cada lector contrae un compromiso con el texto que tiene ante sí, al cual puede responder sin renunciar a su libertad siempre y cuando sí abandone, vol untariamente, la "pereza" y la "ignorancia" de las lecturas borreguiles, las cuales son incompatibles con el ejercicio de la lectura responsable (García L anda 1998: 445-49). 
rreflexivo con "little narratives" al ternativas, representada cada una por un personaje femenino secundario. A ntes al contrario, nuestra protagonista se refugia en la nueva fidelidad profesada a la imagen monolítica de su yo, mantenida al margen de la reflexión crítica, con lo cual evita el compromiso de la indagación ética descentralizadora (2002: 93).

A utores como K earney o Larrosa sugieren que el lector, en su relación con un texto ético de gran intensidad emocional, realiza un doble movimiento de entrada y salida imaginativas. La misma metáfora anima el trabajo de M arshall Gregory, para quien el lector cívico de novelas de formación debe confiar en sus emociones éticas (o en la ética de las emociones espontáneas) a la hora de relacionar una historia ficticia con el contexto vital en el cual se desenvuelve como sujeto. L o que dicho lector no debe hacer, continúa este escéptico de la teoría crítica, es desvirtuar la fuerza emocional del " 'going out' " imaginativo al encuentro del otro (la "'assentive' reading") con el subsiguiente cuestionamiento apriorístico (ético y estético) del texto, que él Ilama primero "postmodern theory" y posteriormente, de manera más arbitraria, "uninformed resistant reading" (1997: 45$46,49)$. Gregory opina que la teoría postmoderna, al revés que la experiencia inmediata del texto literario, propaga el ideal de un lector excesivamente beligerante, obsesivo e intolerante, interesado sólo en dinamitar el consenso existente sobre esta 0 aquella cuestión. G regory se olvida de que precisamente la literatura ha sido percibida, a lo largo de la historia, como una forma de subversión del orden social establecido, y, lo que es más importante, de las barreras que el superyó pone al inconsciente para que el sujeto no haga libre uso de sus instintos de autoafirmación más irreductibles. Esto es así porque, como muestran Burke y L arrosa a lo largo de sus estudios respectivos, la literatura permite al lector asomarse al umbral de lo irracional sin que ello le suponga dejarse succionar por el vórtice de la intoxicación y la locura.

L a lectura ética que propone $G$ regory presenta un grave inconveniente. A I presuponer que las actitudes recelosas y beligerantes de un lector frente a una determinada novela, construidas sobre la llamada "hermenéutica del recel o" (la frase es de Paul Ricoeur, aunque Gregory se la apropia sigilosamente [1997: 47]), no hacen sino entorpecer la relación ética más espontánea y abierta, lo que consigue es animar al lector a que reproduzca la misma economía profiláctica que inspira la composición de la novela. Para evitar esta interiorización inconsciente es necesario dar un sal to interpretativo desde la mera figuración metafórica-como intoxicacióndel discurso novelesco hasta la contextualización crítica del mismo como disfunción psicosocial del personaje. La autora de The Awakening intencionadamente siembra su texto de imágenes narcóticas hasta el punto de desarrollar diegética- 
mente una metáfora extensa de lo que he dado en llamar, a través de mi préstamo de B urke, la profilaxis imaginativa. A hora bien, como Chopin crea una protagonista que no participa en dicha actividad profiláctica, lo cual la separa del resto de personajes, es imprescindible que transcendamos el umbral metafórico de la profilaxis para explorar el umbral crítico de la teoría postmoderna. D esde el momento en que aceptamos la existencia de esta diferencia y esta necesidad, se nos plantea la cuestión de cómo compaginar la indagación ética con la teoría crítica, ordenando ambos quehaceres en una misma secuencia interpretativa.

La representación en The Awakening de personajes que participan en la economía y terapéutica profilácticas junto a otros que se resisten a participar en dicha economía y terapéutica y, por consiguiente, a contraer compromisos responsables con el texto de sus vidas sociales, subraya aún más si cabe las virtudes didácticas de la obra de Chopin como novela de aprendizaje ético en la administración de las emociones y de iniciación a la lectura crítica. Dicha lectura podría comenzar con la constatación, desarrollada ya en la primera parte de este ensayo, de que Edna sustituye su dependencia totalitaria de la disciplina doméstica (su rol de mujermadre) por su dependencia totalitaria del impulso romántico (su rol de paseante solitaria). Lo cierto es que la autorreflexividad psicológica y crítica le hubiese permitido a Edna complementar y dosificar la indudable y provechosa carga afectiva de la literatura. La integración de ambas facetas en un solo ejercicio de exégesis es, de hecho, el mayor desafío didáctico con que se enfrentan tanto el lector empírico de The Awakening como la protagonista de la novela. El autoexamen personal (sea psicoanalítico o socrático) y la reflexión teórica sobre la obra narrativa conllevan un "deceleration effect"; tienen un ritmo lento que nos anima a profundizar en nuestra interioridad y en el objeto de nuestra búsqueda sin que nos precipitemos a conclusiones apresuradas (Fuss 1994: 103-04, 112; Readings 1996: 67-68, 147$49)^{14}$. Dicho con otras palabras, el enfoque teórico de la literatura no está necesariamente reñi do con el enfoque ético (como proclama Gregory), sino que lo cual ifica y complementa según cambian los contextos sociales en que se realiza la lectura. A sí pasaríamos, en fases consecutivas de la recepción, de la inmersión imaginativa en el texto a su contextualización lectora como análisis crítico.

The Awakening presenta un ejemplo sumamente interesante de desenlace polémico y de difícil dilucidación, cuya interpretación detallada agradece, casi diríamos que requiere, la mediación de la teoría, en concreto de la teoría psicoanalítica.

14. En otro lugar he examinado en detalle las propuestas pedagógicas de R eadings y su posible aplicación al entorno institucional de la universidad española (2002: 160-61, 175-76, 178-80). 
M e refiero, claro está, a la ambigua presentación, con técnicas impresionistas y una cuidada utilización del estilo indirecto libre, de la solitaria y perturbadora muerte de la protagonista, quien voluntariamente se aleja, mar adentro, de la orilla de la playa a la que ha acudido sola, con la intención última de ahogarse. La narradora evita omitir un juicio moral de este acto, como también evita mencionar directamente el deseo de Edna de suicidarse, dejando que el lector, a la vista de la conducta anterior del personaje y de sus actos presentes, saque sus propias conclusiones. El lector tiene la ilusión de acceder a los contenidos de la conciencia desnuda de Edna. M ientras ésta nada hacia el interior del océano, en su conciencia se agolpa una sucesión de imágenes de romanticismo desbordado: la niña que atraviesa las praderas azules de K entucky; el sonido de las espuel as del oficial de caballería que acostumbraba a visitar la casa familiar para charlar con el padre; y los oráculos líricos de la bohemia M ademoiselle Reisz, los cual es comparan a Edna con un pajarito que no llega a alcanzar la libertad por habérsele roto un ala en su precipitada escapada ${ }^{15}$. De esta forma parecemos asistir, como lectores, al nacimiento de una poeta más que a la muerte de una persona automarginada y desorientada.

Un lector escapista e impresionable podría emular las respuestas lectoras de Edna, cumpliendo así el primer paso de identificación empática con el personaje, si bien luego podría asimismo experimentar dificultades para distanciarse de él y comenzar la lenta labor de la crítica ética y la mediación teórica. Estas dificultades surgen a pesar de que la narradora continuamente Ilama nuestra atención sobre la impaciencia de $E$ dna, su desinterés por los hijos que, condicionada o no por su sociedad, ha traído al mundo, y su completo abandono a la embriaguez romántica ${ }^{16}$. Edna, tras rechazar el texto y el rol sociales de la existencia doméstica y conyugal, se vuelca por completo en el texto de la transgresión y la búsque-

15. M erece la pena destacar el cambio de actitud de Edna frente a M ademoiselle Reisz en el transcurso de la narración. Pasa de negarse a escuchar las críticas que la pianista hace de los personajes más conformistas, por considerarlas un "venom" (150), a hacer de esta excéntrica mujer, en ausencia de Robert, su principal interlocutora y confidente (a partir del capítulo XX). La implicación de este proceder es que Edna se envenena con la conversación de M ademoiselle Reisz, quien sin embargo no se intoxica a sí misma debido a su capacidad para controlar la economía profiláctica de las emociones. La propia E dna responde así a la insinuación de A robin de que la pianista está "partially demented": "She seems to me wonderfully sane" (194). A caso tampoco sea accesorio el dato de que la arisca amiga de Edna es el único personaje, entre los veraneantes de $\mathrm{G}$ rand Isle, que aborrece los baños de mar, lo cual, en consecuencia, la pone a salvo de la seductora voz del océano (149-50).

16. Me refiero a pasajes en los cuales la narradora afirma que M r. Pontellier se preocupa más por los niños de lo que lo hace $\mathrm{Edna}$, quien, debe recordarse, tiene por lo menos tres sirvientes domésticos (97-99). N ótese asimismo que E dna sentimentaliza la relación materno-filial, pero olvida su condición de madre tan pronto como logra deshacerse de sus niños para estar sola, una situación recurrente en la novela $(112-13,209)$. 
da sin fin de un proyecto de vida en sí inefable. Puesto que este deseo romántico es un imperativo totalitario del ego, que en su expresión más plena no admite medias tintas ni compromisos, Edna termina llevando al extremo de la autodestrucción sus ansias simultáneas de liberarse de todo compromiso familiar y social y de fundirse con una realidad que transcienda el control de la razón ${ }^{17}$. Como el símbolo en que objetiva dichos deseos es el océano, que la trata a un tiempo como una madre que mece a su hija y un amante que la acaricia, Edna completa su equívoco despertar suicidándose en mar abierto.

Las dos interpretaciones más exhaustivas del final de la novela, ambas basadas en textos filosóficos y artísticos de la época en que aparecen casi las mismas metáforas en situaciones análogas, refuerzan la censura autorial realizada a través de imágenes más que de argumentos. A sí, para Sandra M. Gilbert la inmersión en el océano de Edna, completamente desnuda, debiera concluir, según el mito finisecular de la New Woman, con su reaparición transformada en una nueva Venus A frodita (situación recurrente en la literatura y las artes escénicas anglo-norteamericanas del fin de siglo), que actuaría así de portadora de una nueva identidad femenina (1984: 32-33). Lo irónico del caso es que, presumiblemente, Edna no intenta renacer a una nueva existencia, sino, por el contrario, eliminar cualquier posibilidad de que en el futuro los demás puedan achacarle su falta de responsabilidad hacia las personas de su entorno afectivo. M ás reveladora aún que la de Gilbert ha sido la mediación teórica de Cynthia Griffin Wolff, según la cual Edna presenta la patología regresiva que en EI malestar en la cultura Sigmund Freud Ilamó "sentimiento oceánico", a saber, el impulso narcisista por el cual el sujeto rechaza la economía placer/displacer del mundo social, para en su lugar identificarse con un entorno igual mente externo a él, pero anterior 0 ajeno a las divisiones y los gravámenes sociales. En la novela de Chopin, el océano físico adquiere la connotación imaginativa de seno materno, en concreto de líquido amniótico que aísla y protege a Edna de la amenaza exterior del porvenir adulto, aun cuando dicho aislamiento metafórico, al ser de nuevo literalizado en el elemento físico del mar, conlleve a la postre la muerte (Wolff 1976: 209-10, 217-18; Freud 1970: 7-17) ${ }^{18}$.

17. En su controvertido análisis del personaje de Edna, realizado desde la óptica de la "evidentiary philosophy of rights", Dimock tilda a la protagonista de Chopin y a sus apologistas de actitudes "essentialist" y "absolutist", precisamente por no reconocer la vulnerabilidad de los niños y los sirvientes y por intentar construir, sobre una emoción subjetiva (i.e., "si me reconozco madre soy esclava; si abjuro de la maternidad, soy libre"), unos principios éticos y jurídicos falaces (1990: 46-47; 1996: 220-21).

18. González Groba ofrece un resumen pormenorizado de los argumentos en favor y en contra de la interpretación del suicidio como desarticulación de los mecanismos sociales represores de la libertad femenina (1997: 78-88). 
El feminismo entendido como plataforma cívica, practicado al margen de modas teóricas y de visiones románticas de una feminidad sin ataduras, también ha visto la trayectoria vital de Edna como una innecesaria y obcecada marcha hacia la autodestrucción. Así, por citar un ejemplo cercano a nuestro entorno inmediato, la profesora y ex-ministra Carmen A lborch, en su libro Solas, relaciona a la protagonista de Chopin con otras tres heroínas de la novela de adulterio (Emma B ovary, A na K arenina y A na Ozores), comparación que la lleva a suscribir la tesis de que "Edna Pontellier toma conciencia de su despertar como ser humano, de sus ansias de independencia física, emocional y económica, y ante la inviabilidad de sus deseos se suicida" (1999: 50) ${ }^{19}$. También el historiador A ndrew Delbanco ha señalado que Edna sale de una situación de alienación para meterse en otra, sin que llegue a dosificar correctamente los efectos potencialmente liberadores, a la par que destructores, de ninguna de sus el ecciones de vida, hasta el punto de que ella misma "recognizes in her 'awakening' a new form of degradation. She swims to her death not... in a kind of ecstatic suicide amid the warm Gulf waves, but in despair at not having found a third way between the alternatives of submission and emulation" (1997: 132).

U na manera muy interesante en que The Awakening se presta a usos didácticos es en su búsqueda de una nueva dimensión, específicamente feminista, para el exhausto naturalismo finisecular. En su novela, Chopin trata las crisis de identidad femenina no como una patología, sino como un proceso psicológico normal por el cual una mujer cuestiona los roles sociales que le han sido impuestos consciente 0 inconscientemente. Sin embargo, en su despertar Edna incurre en una aceleración excesiva de la autoindagación y en la negativa a controlar, en pequeñas dosis homeopáticas, sus nuevas lecturas y experiencias románticas, todo lo cual redunda en una intoxicación emocional de consecuencias fatales ${ }^{20}$.

19. Resulta instructivo comparar The Awakening con una novela corta veladamente misógina, aunque muy valiente en su denuncia del olvido social de los más pobres, a cargo de una autora contemporánea de Chopin: Edith W harton. En Ethan F rome (1911) W harton retrata a un protagonista masculino que también experimenta un despertar imaginativo y erótico, planea una fuga con su interlocutora, pero finalmente opta por un conato de suicidio. Véase Rodríguez García (1998: 125-27).

20. La novela, de hecho, participa a un tiempo de las convenciones del naturalismo moralizador (quien desafíe el orden social será castigado) y de la introspección feminista (no debe haber límites a la exploración de la subjetividad femenina). V éase a este respecto el interesante estudio de I barrola (1998: esp. 119-21, 131-32), quien busca flexibilizar ambos moldes literarios para así hacerlos compatibles. Por el contrario, para estudiosas feministas como A mmons, "The Awakening dramatizes oppositions, theses and antitheses, for which no synthesis materializes, no dialectic is conceivable, because the oppositions exist within white western culture itself, over which Edna especially as a woman, has no control" (1991: 73). 
En conclusión: The Awakening permite el doble ejercicio de la identificación empática del lector con un atractivo personaje (a través de una proyección psicológica) y el posterior distanciamiento crítico de éste (a través de una toma de postura ética y crítica). Para expresarlo con palabras ya traídas a colación en este ensayo, un mismo texto de fuerte carga romántica o simplemente emocional puede inducir una experiencia de vacunación alopática (rechazo instantáneo de las experiencias de uno de los personajes) o de empatía enajenante (intoxicación en la lectura solitaria y abusiva). La primera reacción fue la más generalizada entre los críticos tempranos de Chopin, mientras que la segunda abunda especialmente entre los lectores contemporáneos, más sensibles a la lenta lucha por la conquista de la autonomía que ha caracterizado la historia de las mujeres ${ }^{21}$. La ventaja inherente a la proyección empática es que, como han argüido Nussbaum y Gregory (entre muchos otros), el lector solitario normalmente no inhibe sus emociones más intensas, al go que sí haría en situaciones reales. En consecuencia, la literatura puede ser un catal izador de la reflexión crítica más eficaz aún que los discursos de denuncia, ante los cuales el lector con frecuencia adopta una postura defensiva y escéptica ${ }^{22}$. Visto así, el ejercicio de la lectura solitaria sería una preparación idónea para la posterior práctica homeopática, es decir, para la desintoxicación parcial en el debate crítico y teórico que proporciona la clase de literatura.

21. Tras su publicación en Chicago, como volumen suelto, en 1899, la novela de Chopin concitó el desprecio airado y casi unánime de tres grupos de críticos: los más conservadores, que la consideraron inmoral (porque la narradora no condenaba explícitamente la infidelidad de una mujer casada); los más apegados al realismo, que la consideraron torpe (porque el final impresionista y fragmentario era bastante sorprendente y postulaba un tipo de lector más activo que el formado en las convenciones del realismo); y los que hubiesen deseado (como Willa Cather) un mayor protagonismo de la autoctonía norteamericana, que lamentaron justo lo opuesto- el aparente determinismo de la trama provocado por el intertexto flaubertiano. The Awakening volvería a editarse póstumamente en N ew York, en 1906 (Chopin muere en 1904), para después caer en el olvido. En 1964 K enneth Eble la devuelve a la vida editorial, siendo posteriormente incluida por Per Seyersted en una antología crítica de obras de la autora, en 1966, y en la colección de obras completas publicada en 1969. La novela al canzaría estatuto canónico a partir de 1976, cuando $\mathrm{M}$ argaret Culley, en la estela del creciente reconocimiento académico de la crítica feminista, da a la imprenta la edición de Norton, que incluye numerosos documentos históricos y una valiosa selección de artículos para el estudio de la obra.

22. V éase Nussbaum (1990: 48-52); Gregory (1997: 51, 55-56); Rodríguez García (1998: 136). 


\section{Bibliografía}

A LBORCH BATALLER, Carmen. 1999. Solas. G ozos y sombras de una manera de vivir. 6a ed. Madrid: Temas de Hoy.

A M M ONS, Elizabeth. 1991. Conflicting Stories: American Women Writers at the Turn into the Twentieth Century. New York: Oxford UP.

BURKE, K enneth. 1984a. Attitudes toward History. 1937. 3a ed., rev. B erkeley: $U$ of California $P$.

- 1984b. Permanence and Change: An Anatomy of Purpose. 1935. 3a ed., rev. Berkeley: U of California P.

- 1964. Terms for Order. Ed. Stanley Edgar Hyman y Barbara Karmiller. Bloomington: Indiana UP.

CATHER, Willa [pseudónimo: "Sibert"]. 1976. "A Creole Bovary... (from the Pittsburgh Leader)". 1899. Reimpr. en Culley 1976b: 153-55.

CHOPIN, Kate. 1997. The Awakening (El despertar). 1899. Ed. Constante González Groba. Salamanca: Ediciones Colegio de España.

CULLEY, M argaret. 1976a. "The Context of The Awakening". En Culley 1976b: 117-19.

- ed. 1976b. The Awakening: A Norton Critical E dition. New York: Norton.

DELBANCO, Andrew. 1997. Required Reading: Why Our American Classics Matter Now. New York: Farrar.

Diccionario enciclopédico de las ciencias médicas. 1985. Ed. Alfonso R. Gennaro et al. Trad. de la 4a ed. inglesa. M éxico: M cGraw-Hill.

DIMOCK, Wai Chee. 1990. "Rightful Subjectivity". The Yale Journal of Criticism 4: 25-51.

- 1996. "Rights and Reason". Residues of J ustice: Literature, Law, P hilosophy. Berkeley: $U$ of California P. 182-223.

FREUD, Sigmund. 1970. El malestar en la cultura y otros ensayos. Trad. Ramón Rey A rdid et al. M adrid: A lianza.

FUSS, Diana. 1994. "A ccounting for Theory in the Undergraduate Classroom". Teaching Contemporary Theory to Undergraduates. Ed. Dianne F. Sadoff y William E. Cain. New York: M LA of A merica. 103-13.

GARCÍA LANDA, J osé. Á ngel. 1998. Acción, relato, discurso. Estructura de la ficción narrativa. Salamanca: Ediciones U niversidad de Salamanca.

GILBERT, Sandra M. 1984. "Introduction: The Second Coming of A phrodite". The Awakening and Selected Stories. Ed. S.M. Gilbert. Harmondsworth: Penguin. 7-33.

GONZÁ LEZ GROBA, Constante. 1997. "Introducción". The Awakening (EI despertar). Por K ate Chopin. Salamanca: Ediciones Colegio de España. 9-88. 
GREGORY, M arshall. 1997. "The Many-Headed Hydra of Theory vs. the Unifying M ission of Teaching". College English 59: 41-58.

IB A R ROLA , A itor. 1998. "Tenuous Feminism and U northodox N aturalism: K ate Chopin's Unlikely Literary Victory at the Close of the 19th Century". Revista de Estudios Norteamericanos 6: 107-32.

KEARNEY, Richard. 2002. "Ethics of the Narrative Self". Between Philosophy and Poetry: Writing, Rhythm, History. Ed. Massimo Verdicchio y Robert Burch. N ew York: Continuum.

LARROSA, Jorge. 1996. La experiencia de la lectura. Estudios sobre literatura y formación. B arcelona: Laertes.

L OUREIR O, Ángel G. 2000. The E thics of Autobiography: Replacing the Subject in Modern Spain. N ashville: Vanderbilt UP.

NUSSBA UM, M artha C. 1990. Love's Knowledge: Essays on Philosophy and Literature. New York: Oxford UP.

RANKIN, Elizabeth. 1988. "A Reader-Response Approach". Approaches to Teaching Chopin's The Awakening. Ed. Bernard K oloski. New York: M LA of A merica. 150-55.

REA DINGS, Bill. 1996. The U niversity in Ruins. Cambridge: Harvard UP.

RODRÍGUEZ GARCÍA, J osé M aría. 1998. "Escritura ética y escritura epitáfica en E dith W harton, Henry J ames y Stephen Crane". Interpretations of E nglish. Essays on Literature, Culture and Film. Ed. Isabel Moskowich-Spiegel Fandiño et al. A Coruña: U niversidade da Coruña. 121-37.

- 2002. "L a universidad de la cultura, la universidad del disenso y la Tercera Vía universitaria (N orteamérica y España)". Arizona J ournal of Hispanic Cultural Studies 6: 151-90.

SCHWEITZER, Ivy. 1994. "Maternal Discourse and the Romance of SelfPossession in Kate Chopin's The Awakening". Revisionary Interventions into the Americanist Canon. Ed. Donald E. Pease. Durham: Duke UP. 158-86.

SHOWA LTER, Elaine. 1994. "Tradition and the Female Talent: The Awakening as a Solitary B ook". N ew Essays on The Awakening. Ed. Wendy M artin. 1988. Reimpr. con revisiones. Cambridge: Cambridge UP. 33-57.

WOLFF, Cynthia Griffin. 1976. "Thanatos and Eros: Kate Chopin's The Awakening". American Quarterly 25 (1973). Reimpr. en Culley 1976b: 206-18. 